\title{
Service-Learning at the Postgraduate Level to Reach Depressed Sectors of Society
}

\author{
José S. Torrecilla \\ Universidad Complutense de Madrid
}

John C. Cancilla

Scintillon Institute

\author{
Esther Lopez-Martin \\ Universidad Nacional de Educación a Distancia (UNED)
}

\begin{abstract}
Currently, a substantial change is being demanded from Higher Education, which should be oriented towards innovation with a much more practical approach. To obtain these objectives, the collaboration between society, which presents a need, and the University, which offers alternatives, is sought. This integration could be guided by "Service-Learning", which aims to link society with academic institutions, promoting the enrichment, not only of the host community, but also by training students. This paper presents a Service-Learning project linked to doctoral studies which present technological developments to people in society who are in danger of exclusion.
\end{abstract}

Keywords: service learning, infrared thermography, chemical engineering, teaching, social integration

\section{INTRODUCTION}

Many of the shortcomings that affect our society should serve to frame the training procedures of our future professionals (Martinez, 2007). In numerous occasions, these social problems should catalyze the design of a training channel for students in order to offer a way to solve and manage current resources. Nowadays, the reconciliation of educational aspects and social inclusion offers advantages that can solve not only the deficiencies of society itself but also educational considerations such as aspects related to personal effort, ethical and civic values, social responsibility, solidarity, etc. This reconciliation needs to be integrated within an educational proposal that combines learning and service to the community in a single plan. A project where its members learn to work in a real environment where the current needs are presented, and the main purpose is to improve its deficiencies. This offer is embedded in what has been called the methodology of service-learning (SL). It is an educational approach based on experience, in which the students themselves dedicate their time to helping the community and, at the same, time their training is facilitated, making it easier for them to achieve their sought professional skills (Annette, 200; Rodriguez, 2014). Tapia describes the SL methodology as an "activity or program of solidarity service led by the students, oriented to efficiently attend to the needs of a community and planned in an integrated 
manner with the curricular contents with the objective of optimizing learning" (Tapia, 2008). SL represents an innovative educational proposal that brings together the learning of contents, competencies, and values with the performance of community service tasks (Tinkler et al., 2019). In this way, students, along with the concepts they acquire, extend beyond the classroom to learn about the importance of their presence and competence for society in the area of service.

However, it is necessary to differentiate this methodology from others that present deficiencies in different areas, some in aspects of learning and others in aspects of solidarity. Specifically, it is necessary to distinguish the methodologies linked to SL from other activities such as workshops, community service, or volunteer activities (Rodriguez, 2014). SL is a methodology that presents positive aspects in three welldifferentiated areas of student training: (i) it improves the academic curriculum by focusing on more practical training and adaptation of theoretical knowledge to make it more applicable in a social approach within the professional environment; (ii) training in values, which in the future of the student will have a relevant influence on both the student and his or her reflection on society; (iii) bonding with the community since the activities linked to SL respond to a professional intervention on a real social issue (Rodriguez, 2014). Manzano asserts that an activity cannot be understood as belonging to the SL methodology if it does not present four important characteristics: orientation towards society, presence of students in the activity, academic learning, and horizontal dialogue with society (Manzano, 2010) ${ }^{7}$

In this environment, the activities linked to SL bring together training aspects that in today's learning are distant and, in some cases, completely inexistent, such as combining theory with practice, classroom with real problems, or training with commitment (Butin, 2006; Manzano, 2010). So much so that Martinez argues that quality university training cannot separate professional instruction from citizen training (Martinez, 2007, Rodriguez 2014). This is why in recent years a large number of universities are actively implementing SL methodologies in numerous degrees they teach. This has even led to the implementation of institutional programs in this area. In some European organizations ("Lernen durch Engagement", Germany), voluntary work placements are being replaced by SL activities. Networks are also being promoted to facilitate the joint development of this type of activity (Rodriguez 2014).

The implementation of SL represents a great advance in the pedagogical field for all levels and ages, including universities (Dillabaugh, 2019; Sewry, 2018). Beyond that, it is not only focused on university degree students, but also on master's students, doctoral students, and even post-doctoral students. Trying to take a step forward, this methodology is also being transferred to the area of research training. Specifically, it would be very interesting if the research being carried out in the universities' own research laboratories were to be brought out into the open with the aim of informing the society about the knowledge that is being generated (Sewry, 2018; Saitta, 2011). Likewise, to communicate and promote the generation of more knowledge, as the society can reveal its main needs (Ching, 2018). In this way, meaningful learning would be valuable for university students, but also would empower a response to meet society's needs. The application of this methodology in the university would not only foster the standards of solidarity, but also the integration of different communities, stimulating mutual appreciation.

The aim of this work is to employ SL activities to training researchers during their doctoral period. Consequently, these SL experiences will be focused on the development of technological applications based on artificial intelligence in the fields of food and health. To this end, results of research projects being carried out by doctoral students will be used: (i) to bring to society the main results obtained regarding technological development; (ii) to have society participate in each of the steps and feel integrated enough to submit their ideas, needs, and potential improvements; (iii) to transmit the criteria of innovation to society and that society itself provides feedback; (iv) to transmit values to students, researchers, and collaborators in the academic field, and that the service becomes a workshop of values and knowledge; (v) to favor university-society integration. The activities have been carried out for people at risk of social exclusion who gather at centers belonging to the Madrid City Council. Specifically, in different centers belonging to the Department of Social Inclusion for Community Integration and Social Emergency of the Madrid City Council (Spain). 


\section{METHODOLOGY}

In this paper we present a model of SL that has been developed within different PhD studies in the Chemical Engineering program of the Chemistry division of the Complutense University of Madrid (UCM) (Spain). This model has been implemented during the 2018-19 and 2019-20 academic courses (previous and current year). This development is focused on the design of a SL activity integration plan within the work of the $\mathrm{PhD}$ students. It also studies the impact of this integration within the training phase of a researcher. The team is formed by four professors, six students ( $\mathrm{PhD}$ students), and 120 students from day or host centers (130 people involved). Within the design of the research, it should be noted that the people being presented with the novel technological tools currently being developed have a notably lower level of education. In addition to providing knowledge of the technologies, they are given the possibility to develop their imagination. This time and their enthusiasm and effort will notably enhance their overall understanding of the topics, imagination, and capability to present ideas. Within the development phases of the model presented in this work, eight sequential phases are contemplated (Rodriguez, 2014):

i. Diagnosis: it is necessary to know not only the human resources available, but also the situation and the specific problems of the community where the model is aimed. It must be considered that $99 \%$ of the people at whom the model is aimed are in a situation of social disadvantage, have suffered alcohol and/or drug addiction, and/or are under a psychiatric treatment which can hinder their cognitive abilities.

ii. Initial coordination: for the development of the model, a project was written by the teachers in the consortium. This project established the guidelines for the collaboration between the teachers and the SL students. Before starting, it was necessary to contact the schools and make a series of visits to know in detail where the SL model was going to be applied. In this case, the staff and technicians of the centers themselves informed us about their lines of interest.

iii. Design: since we had to match activities within the university, several coordination meetings were held where each of the postgraduate students organized their schedules to fit with the centers, which was mostly in the morning. They also had to start working out common strategies to carry out the activities. The overall dedication of each student to these activities was two ECTS credits (50 hours).

iv. Execution: two activities were carried out for totally different audiences. Those that were closer to society and to the interest of the target audience were selected.

The first activity, entitled "From Heart to Stroke - Food and Innovation", was presented on 7 March 2019 at the facility of the Dual-Candelita Association (figure 1). In this first activity, a workshop/conference was held related to the application of technologies developed by the AlgoReach research group regarding the prevention of stroke and various cardiovascular diseases through healthy eating, as well as technologies developed in various projects of the research group. The number of attendees was around 25 .

The second event entitled "Thermography, a photograph of the human body" was held a week after, on March $13^{\text {th }}$. This event took place at the Faculty of Chemical Sciences of the UCM. The number of attendees was approximately 40 people belonging to different associations. In this event, the research group AlgoReach presented, based on their results, the underlying potential that the measurement of the human body's temperature has. Likewise, measurements were taken from the attendees themselves, explaining in each case the images taken and asking the attendee to express any doubts and curiosities they might have (figure 2). 


\section{FIGURE 1}

\section{IMAGES TAKEN FROM THE EVENT \\ "FROM HEART TO STROKE - FOOD AND INNOVATION"}
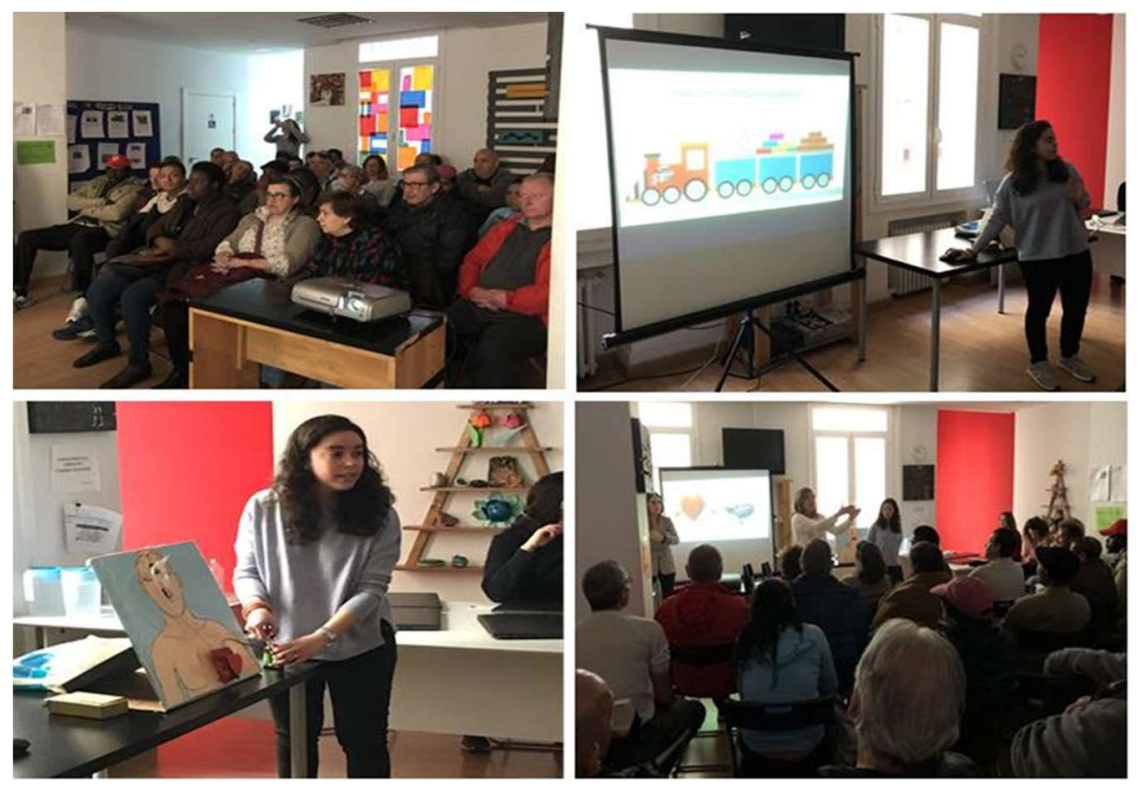

FIGURE 2

IMAGES TAKEN FROM THE EVENT

"THERMOGRAPHY, A PHOTOGRAPH OF THE HUMAN BODY"

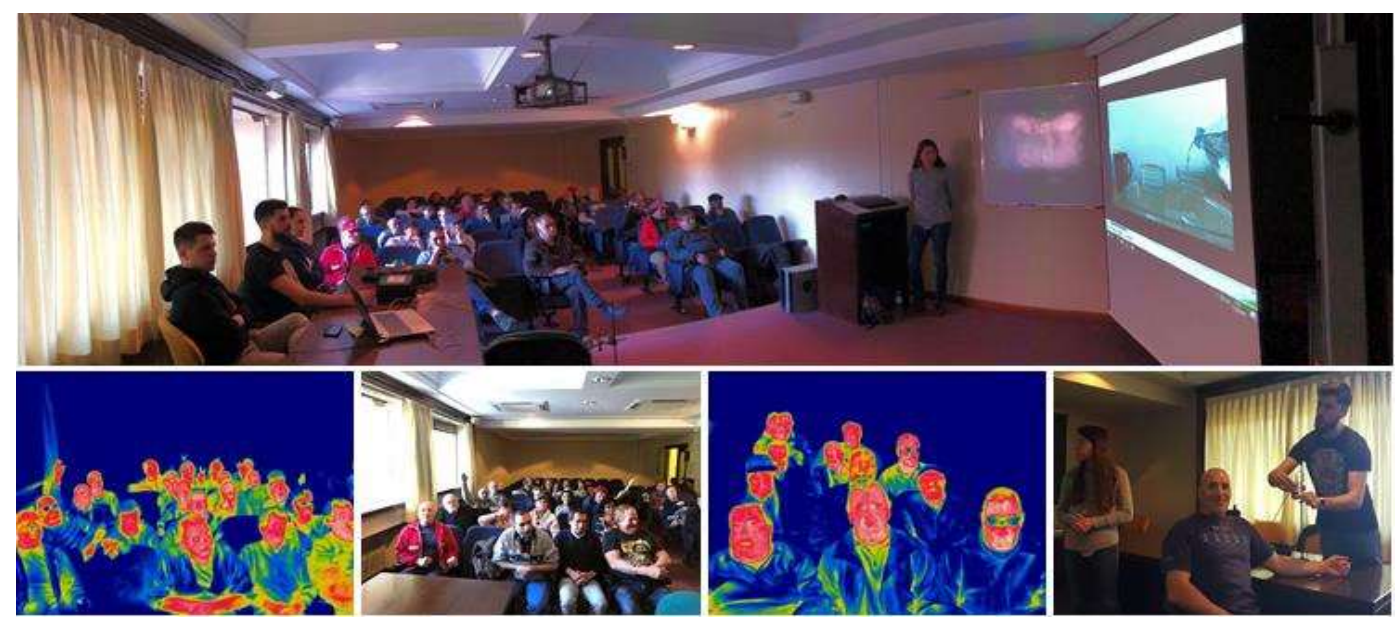

v. Reflection: after each of these events, a report is written and all the necessary information for the preparation of the event in question is gathered. These resources are giving the base of information that will help improve and facilitate other doctoral students in the pursue and design of new events. Likewise, after each event, meetings are held with all the parties involved in order to learn about the relevant aspects and to improve their quality so that it responds to all the initially marked specifications.

On both occasions, these debates were very enriching. In the first case, the speakers, coordinators, and attendees were talking about the importance of research and the factors that affect the appearance of cardiovascular problems. After the second activity, they were 
discussing the economic support for research and the different strategies that the attendees considered most appropriate to get more out of the technique presented, and the research itself.

vi. Evaluation: The evaluation was carried out based on the assessment of the learning acquired by the PhD students who participated in this SL experience. To this end, after the activity, a questionnaire was applied and completed by the three $\mathrm{PhD}$ students.

It should be noted that this questionnaire is based on the Cognitive Learning Scale (Steinke, 2002), but differs from the previous in that it used an open-ended question format and included questions relating to satisfaction with the experience.

vii. Closing and celebration: once the event has finished, certificates for each of the activities are handed out.

\section{RESULTS AND DISCUSSION}

The students' answers to the questionnaire show how two of the three students had previously participated in learning and service activities (Q1) and, consequentially, two of them had previously carried out volunteer activities with different non-governmental organizations (Q2).

All $\mathrm{PhD}$ students consider that the SL experience has helped them to answer questions that had been raised during their studies (Q3). Among others, they make the following appreciations: "I have been able to see a different point of view that has helped me connect knowledge" or "It is an opportunity that reflects what you have studied during your academic formation".

The experience provided an opportunity to consolidate the knowledge they had acquired during their studies, as it allowed them to apply that knowledge to solve real problems (Q4), to broaden their knowledge (Q5), to develop their own examples of the principles and concepts they studied in class (Q6), to appreciate the importance of the issues they had learned (Q10), and to gain a deeper understanding of the subject (Q11). All students respond affirmatively to the above questions, making, among others, the following remarks:

"The experience has served me to achieve a 'new version' or explanation of the concepts already studied, facilitating their understanding and thus their learning".

"The elaboration of my own examples has meant a different way of consolidating the concepts".

"SL experience has provided a new opportunity to review and assimilate the concepts studied".

In turn, it has helped students develop other skills than those commonly presented in curriculums. All participants reported that they had been able to analyze the complexity of real-life problems and their solutions (Q7), gain a better understanding of the ethical and social issues in their environment (Q8), and understand the logic behind different perspectives on problems affecting their field of study (Q9).

Finally, in terms of satisfaction with the experience, all students indicated that if they had the opportunity, they would repeat the SL experience and would, of course, recommend it to their peers and friends. Among the aspects that they liked the most are the following:

"The way to consolidate the contents addressed in class through practical problems".

"To be able to transmit knowledge to people who do not have the means to learn".

"Personal enrichment achieved through experience". 


\section{CONCLUSIONS}

This paper presents a project through which centers with students at risk of exclusion are integrated with doctoral students by means of the Service-Learning methodology. Although the project continues to develop, the results obtained so far are very satisfactory, from the point of view of professors, doctoral students, and attendees. It should be noted that the $\mathrm{PhD}$ students have acquired social skills regarding community collaboration and at the same time have tied bonds with people that have serious social problems. This synergy has notably fostered not only the knowledge, but also the formation of values and service to the community. So much so that the great results that have been obtained are opening up the possibility of periodically establishing new activities implicit in the technological projects that are set in motion and that those responsible are not only the doctoral students in charge of these lines, but also a novel commission formed for this purpose.

\section{ACKNOWLEDGEMENTS}

This work has been carried out with the financial support of the SL UCM 2018/19_16 project and the Madrid City Council.

\section{REFERENCES}

Annette, J. (2000). Civic participation and education for citizenship. Political Studies Association, UK, $50^{\text {th }}$ Annual Conference. London.

Butin, D.W. (2006). The limits of service-learning in higher education. The Review of Higher Education, 29, 473-498.

Ching, S.H. (2018). Turning a Service-Learning Experience into a Model of Student Engagement: The Lighthouse Heritage Research Connections (LHRC) Project in Hong Kong. Journal of Academic Librarianship, 44(2), 196-206.

Dillabaugh, J. (2019). Liberating Service Learning and the Rest of Higher Education Civic Engagement. Journal of Experiential Education, 42(1), 93-94.

Manzano, V. (2010). El modelo de Aprendizaje Servicio y su potencial para la educación superior. VI Jornadas de docencia en Psicología. Universidad de Sevilla.

Martínez, M. (2007). Formación para la ciudadanía y educación social. Revista iberoamericana de Educación, 42, 5.

Rodriguez, G.M.R. (2014). El aprendizaje-servicio como estrategia metodológica en la universidad. Revista Complutense de Educación, 25, 95-113.

Saitta, E.K.H., Bowdon, M.A., \& Geiger, C.L. (2011). Incorporating Service-Learning, Technology, and Research Supportive Teaching Techniques into the University Chemistry Classroom. Journal of Science Education and Technology, 20(6), 790-795.

Sewry, J.D., \& Paphitis, S.A. (2018). Meeting important educational goals for chemistry through servicelearning. Chemistry Education Research and Practice, 19(3), 973-982.

Steinke, P., Fitch, P., Johnson, C., \& Waldstein, F. (2002). An interdisciplinary study of service-learning predictors and outcomes among college students. In A. Furco \& S.H. Billig (Eds.), Advances in service-learning research, Vol 2: Service-learning research through a multidisciplinary lens (pp. 73-102). Connecticut: Information Age Publishing.

Tapia, M. (2008). Aprendizaje y servicio solidario. Buenos aires: Ciudad nueva.

Tinkler, A., Tinkler, B., Reyes, C., \& Elkin, S. (2019). Critical Service-Learning: Learning Through Experience to Advance Teacher Education. Journal of Experiential Education, 42(1), 65-78. 